\title{
Cooking attenuates the ability of high-amylose meals to reduce plasma insulin concentrations in rats
}

\author{
Marc A. Brown ${ }^{1}$, Leonard H. Storlien ${ }^{1}$, Ian L. Brown ${ }^{2}$ and Janine A. Higgins ${ }^{3 *}$ \\ ${ }^{1}$ Metabolic Research Centre, Faculty of Health and Behavioural Sciences, University of Wollongong, \\ New South Wales 2522, Australia \\ ${ }^{2}$ Penford Food Ingredients Co, Englewood, Colorado 80112, USA \\ ${ }^{3}$ University of Colorado Health Sciences Center, Center for Human Nutrition, Denver, Colorado 80262, USA
}

(Received 21 September 2001 - Revised 27 January 2003 - Accepted 11 June 2003)

Postprandial glycaemic control is important in the prevention and therapy of type 2 diabetes and related diseases. Agents that may reduce postprandial glycaemia and/or insulinaemia, such as consumption of high-amylose foods, are considered beneficial; however, little is known about the dose-response relationship and the effects of cooking. The aim of the present study was to define the dose-response curve for postprandial glycaemic and insulinaemic excursions following meals of different amylose content and to compare the dose-response curves for meals containing cooked and uncooked starches. Following an overnight fast, rats ingested a test meal and blood was sampled over $2 \mathrm{~h}$. The meal was given at $1.0 \mathrm{~g}$ carbohydrate $/ \mathrm{kg}$ body weight, with an amylose content of $0,270,600 \mathrm{or} 850 \mathrm{~g} / \mathrm{kg}$ total starch. The area under the glucose curve did not differ under any condition investigated. For the uncooked-starch diets, area under the insulin curve was higher for the $0 \mathrm{~g}$ amylose $/ \mathrm{kg}$ total starch meal than all other meals $(P=0.0001)$. For the cooked-starch diets, area under the insulin curve was higher in the 0 than the 600 and $850 \mathrm{~g}$ amylose $/ \mathrm{kg}$ total starch groups $(P<0 \cdot 01)$, but did not differ from the 270 amylose $/ \mathrm{kg}$ total starch group. These results suggest that even a relatively small proportion of uncooked amylose $(270 \mathrm{~g} / \mathrm{kg}$ total starch) is sufficient to achieve a maximal attenuating effect on postprandial insulin concentrations as compared with $0 \mathrm{~g}$ amylose/kg total starch. Following cooking, however, a much higher proportion of amylose $(\geq 600 \mathrm{~g} / \mathrm{kg}$ total starch) is needed to achieve a similar effect.

Amylose: Amylopectin: Cooking: Insulin

It has long been recognised that there are major differences between simple sugars and complex carbohydrates with regard to their effects on glucose metabolism and insulin action (Storlien et al. 1988; Higgins et al. 1996). It is further recognised that different complex carbohydrates may have different physiological effects. Two polymers of glucose, amylose and amylopectin, constitute dietary starch. Amylose is a linear polymer of glucose residues linked by $\alpha(1 \rightarrow 4)$ bonds, whereas amylopectin is a branched polymer of glucose residues linked by $\alpha(1 \rightarrow 4)$ and $\alpha(1 \rightarrow 6)$ bonds. Amylopectin is generally rapidly digested and absorbed due to its accessibility to digestive enzymes. Foods that produce such high glycaemic responses have been linked to diseases such as non-insulin-dependent or type 2 diabetes mellitus (Salmeron et al. $1997 a, b$; for review, see Morris \& Zernal, 1999). In contrast, amylose may form helical inclusion complexes due to its structure and interaction with dietary lipids and is less accessible to digestive enzymes and is generally digested and absorbed more slowly. Digestion of highamylose starches therefore leads to reductions in postpran- dial glycaemic and insulin excursions relative to high-amylopectin starches.

Studies in animals have compared the impact of highamylose $v$. high-amylopectin starches on postprandial glycaemic and insulinaemic excursions; however, that work has been conducted using uncooked starches and choosing amylose content empirically according to starch availability, rather than for maximal effect (Byrnes et al. 1995; Higgins et al. 1996). One study has evaluated postprandial insulinaemic and glycaemic responses to meals containing three different amylose contents in healthy subjects (Granfeldt, 1994). However, the range of amylose contents used was limited, as all three forms are considered to have a low amylose content $(<500 \mathrm{~g}$ amylose $/ \mathrm{kg}$ total starch). These starches are rarely consumed raw and it has been proposed that their granular structure might be destroyed by cooking (Annison \& Topping, 1994). This could change the digestibility and ultimately the glycaemic and insulinaemic response to the starch. The work presented here was undertaken to test the hypothesis that there is a linear dose-response curve for amylose ingestion

\footnotetext{
Abbreviation: AUC, area under the curve.

* Corresponding author: Dr Janine A. Higgins, fax +1 303315 3273, email Janine.Higgins@UCHSC.edu
} 
v. glycaemic-insulinaemic response and that cooking significantly attenuates the postprandial reduction in glycaemia-insulinaemia caused by amylose consumption. Therefore, the aim of the present study was to define the dose-response curve for postprandial glycaemic and insulinaemic excursions following meals of different amylose content and evaluate the effect of cooking by comparing meals containing cooked and uncooked starches.

\section{Materials and methods}

\section{Animals and diets}

Male Wistar rats (Rattus norvegicus) were obtained from the Animal Resource Centre (Murdoch, Western Australia, Australia) and were housed in groups of three at the University of Wollongong Animal House. The rats were maintained at $22^{\circ} \mathrm{C}$ on a $12 \mathrm{~h}$ light-dark cycle (lights on 07.00-19.00 hours), with free access to a standard laboratory chow (Young Stock Feed, Young, NSW, Australia) and water. The study was conducted according to the National Health and Medical Research Council (Australia) code of practice for the care and use of animals for scientific purposes.

Diets were prepared as described by Byrnes et al. (1995). All diets contained (\% total energy): carbohydrate 67 (starch 57, sucrose 10); protein 22; fat 11. All diets were identical in composition except for the proportions of amylose and amylopectin included in the starch component. The major forms of carbohydrate were $(\mathrm{g} / \mathrm{kg})$ : amylose 0 -amylopectin 1000; amylose 270-amylopectin 730; amylose 600-amylopectin 400; amylose 850-amylopectin 150. Diets were presented to the animals in an unprocessed, unpelleted form. All starches were derived from maize. Uncooked starches were left in their raw form, while the cooked starches were prepared by dispersing the starch in tap water $(40 \mathrm{~g} / \mathrm{l})$ followed by cooking at $80^{\circ} \mathrm{C}$ in an oil-jacketed kettle for $30 \mathrm{~min}$ prior to spray drying. All starches were cooked at $80^{\circ} \mathrm{C}$ to simulate normal cooking conditions and were spray dried with the temperature maintained at $80^{\circ} \mathrm{C}$ to minimise the possibility of crystals being formed (Siljestrom \& Asp, 1985). This method prevents the resistant starch in the high-amylose starches from forming resistant starch 3, thus making comparisons between groups more relevant, as all groups will contain predominantly resistant starch 2 . The dietary fibre level of the starches was determined using the Association of Official Analytical Chemists' (1995) enzymatic-gravimetric method; this method is accepted for labelling purposes in many countries. Total dietary fibre (dry solids) content was similar and low (approximately $10 \mathrm{~g} / \mathrm{kg}$ ) in both uncooked and cooked forms of the 0 and $270 \mathrm{~g}$ amylose $/ \mathrm{kg}$ total starch. Cooking reduced fibre levels from 161 to $99 \mathrm{~g} / \mathrm{kg}$ in the $600 \mathrm{~g}$ amylose starch $/ \mathrm{kg}$ total starch and from 307 to $193 \mathrm{~g} / \mathrm{kg}$ in the $850 \mathrm{~g}$ amylose $/ \mathrm{kg}$ total starch. Starches were donated by Penford Australia Limited, Lane Cove, NSW, Australia.

\section{Surgery}

At approximately 8 weeks of age (250-300 g; 1 week prior to testing) rats were anaesthetised with an intramuscular injection of $50 \mathrm{mg}$ Ketamine $/ \mathrm{kg}$ followed by an intraperitoneal injection of $30 \mathrm{mg}$ Xylazine $/ \mathrm{kg}$. Rats were surgically fitted with an in-dwelling (intravenous) jugular cannula (Silastic; Dow Corning Corporation, Midland, MI, USA), as described by Pascoe et al. (1992). The in-dwelling cannula was used to withdraw blood and re-infuse erythrocytes during the acute meal test. Post-cannulation, rats were housed individually and given free access to rat chow and water. All rats recovered to preoperative body weight within $3 \mathrm{~d}$ postoperatively and were gaining weight normally within $5 \mathrm{~d}$ of surgery.

\section{Acute meal test}

As there were eight different conditions to be tested $(0,270$, 600 or $850 \mathrm{~g}$ amylose $/ \mathrm{kg}$ total starch, cooked or uncooked), it was not possible to keep the animals' cannulae patent long enough to test all eight diets in each rat. Therefore, each animal received a single, acute meal test. Each diet was tested on a total of seven animals (i.e. seven for each group). To ensure that rats would consume all of the test meal within the allotted time $(15 \mathrm{~min})$, they were meal trained before the test day. Two weeks prior to a meal test, rats were presented with the test diet ad libitum overnight to familiarise them with this diet and prevent neophobia on the test day. Twice over the next week, rats were starved for $5 \mathrm{~h}$ then placed in testing cages and presented with a meal of similar size to that which they would receive during the meal test (approximately $0.4 \mathrm{~g}$ diet). Rats had no exposure to test diet or disruption of normal eating habits for $7 \mathrm{~d}$ prior to the meal test.

On the test day, rats were starved overnight $(15 \mathrm{~h})$. The following morning, the rats were placed in $250 \times 250 \mathrm{~mm}$ wire testing cages and allowed $30 \mathrm{~min}$ to acclimatise before testing commenced. A blood sample $(400 \mu \mathrm{l})$ was taken before the rat was presented with a test meal of $1.0 \mathrm{~g}$ carbohydrate $/ \mathrm{kg}$ body weight $(1.49 \mathrm{~g}$ diet $/ \mathrm{kg}$ body weight). Rats were allowed $15 \mathrm{~min}$ to eat and blood samples $(200 \mu \mathrm{l})$ were taken $10,20,30,45,60,80,100$ and $120 \mathrm{~min}$ after eating commenced. Blood samples were centrifuged for $2 \mathrm{~min}$ at $13000 \mathrm{~g}$. Plasma was pipetted into fresh tubes and stored at $-20^{\circ} \mathrm{C}$ for subsequent analysis of glucose and insulin concentration. Erythrocytes from the $0,10,20$ and $30 \mathrm{~min}$ samples were pooled and resuspended in physiological saline $(9 \mathrm{~g} \mathrm{NaCl} / \mathrm{l})$ to a total volume of $800 \mu \mathrm{l}$. Resuspended cells were infused between the 30 and 45 min blood samples in order to maintain blood volume and packed cell volume during testing. Upon completion of the testing period, rats were killed by intravenous infusion of $150 \mathrm{mg}$ pentobarbitone sodium $/ \mathrm{kg}$.

\section{Plasma assays}

All plasma samples were assayed in duplicate. Glucose concentration was measured using a GOD-PAP glucose assay kit (Boehringer Mannheim, Mannheim, Germany) and analysed using a microplate reader (model 550; BioRad, Hercules, CA, USA). Insulin concentration was estimated with a double-antibody radioimmunoassay using rat insulin standards, $\left[{ }^{125}\right.$ I]insulin and antibodies according to the 
manufacturer's instructions (Linco, St Charles, MO, USA). Radioimmuno-complex pellets, containing insulin, were counted for ${ }^{125} \mathrm{I}$ using an automatic $\gamma$-counter (Wallac Wizard 1480-011; Wallac Turku, Finland).

\section{Statistical analysis}

Results are expressed as mean values with their standard errors using Statistics for Windows (Analytical Software, Tallahassee, FL, USA). The concentration of the fasting plasma sample was used as baseline for calculation of the incremental area under the plasma glucose and insulin curves (AUC). Values below fasting (i.e. 'negative values') did not contribute to the AUC value. Statistical differences between diet groups were determined using an ANOVA with repeated measures and Bonferroni's test for comparison of mean values.

\section{Results}

There was no significant difference in either peak glucose concentration (Fig. 1) or glucose AUC in response to amylose content of the diet or cooking (Fig. 3(A)).

There was a significant difference $(P<0.005)$ in peak insulin values between the $0 \mathrm{~g}$ amylose $/ \mathrm{kg}$ total starch group and all other groups for the uncooked state (Fig. 2(A)). However, there was no difference in peak insulin values between any groups for the cooked starches (Fig. 2(B)). Insulin AUC differed according to the amylose content of the meal for both the cooked and uncooked starches (Fig. 3(B)). For uncooked starches, the AUC for insulin was higher in the $0 \mathrm{~g}$ amylose $/ \mathrm{kg}$ total starch group than all other groups $(P=0.0001)$. In the case of cooked starches, the 0 and $270 \mathrm{~g}$ amylose $/ \mathrm{kg}$ total starch groups exhibited a higher AUC for insulin than the 600 or $850 \mathrm{~g}$ amylose $/ \mathrm{kg}$ total starch groups $(P<0 \cdot 01)$.

There were also differences in the insulin AUC between cooked and uncooked starches with the same amylose content (Fig. 3(B)). Although there were no differences between the cooked and uncooked starches for the 0 and $850 \mathrm{~g}$ amylose $/ \mathrm{kg}$ total starch diets, there was a significant difference for the $270 \mathrm{~g}$ amylose $/ \mathrm{kg}$ total starch diets $(P<0.0005)$ and the $600 \mathrm{~g}$ amylose $/ \mathrm{kg}$ total starch diets $(P<0.01)$.

\section{Discussion}

High postprandial glycaemic and insulinaemic responses are linked to development of type 2 diabetes and related diseases (Salmeron et al. 1997a,b). The present results demonstrate that high amylopectin starches $(0 \mathrm{~g}$ amylose/ $\mathrm{kg}$ total starch group) are readily digestible and provide a high insulinaemic response in either the uncooked or cooked form. Even a relatively small proportion of uncooked amylose starch (270 g amylose/kg total starch) was sufficient to achieve a maximal attenuating effect on postprandial insulin concentrations. Following cooking, however, a much higher proportion of amylose was needed to achieve the same effect. These responses resulted in a linear dose-response curve for the cooked starches, whereas there was no such relationship for
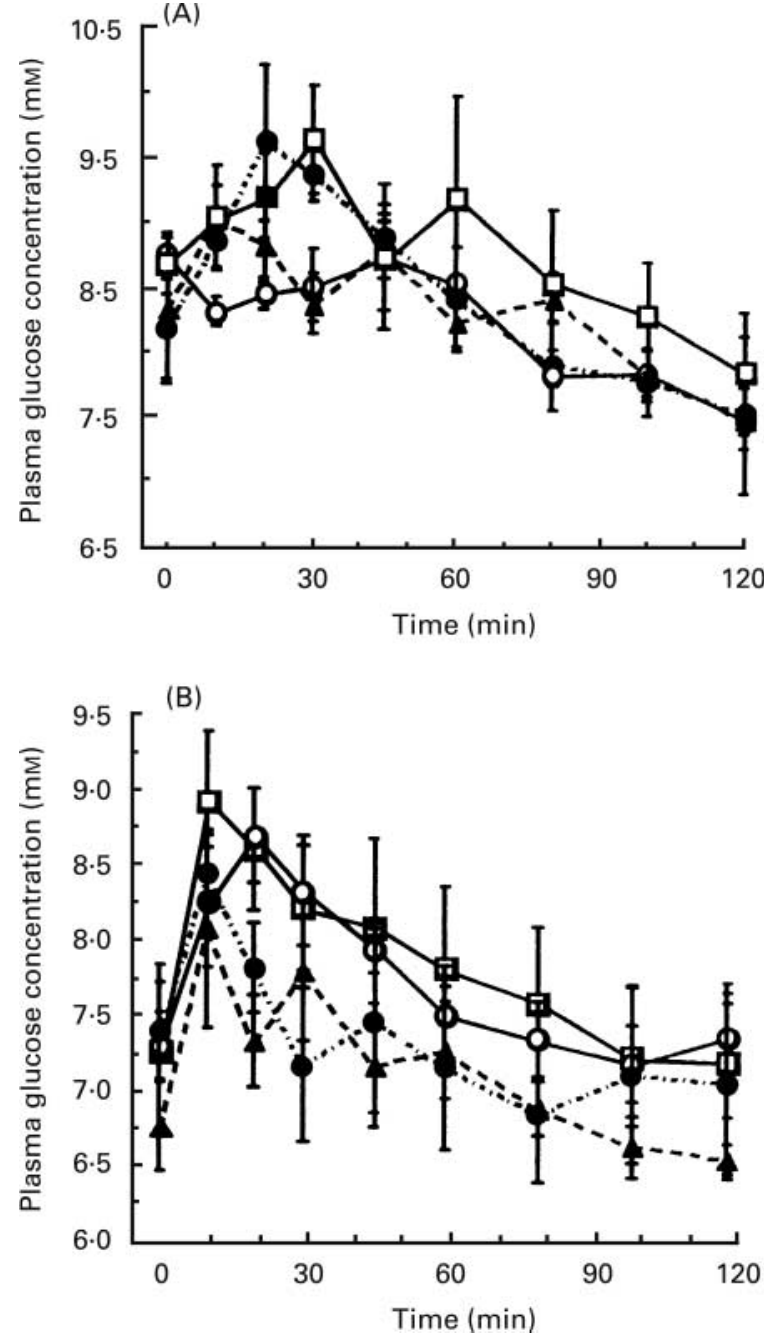

Fig. 1. Postprandial plasma glucose concentrations in response to cooked (A) or uncooked (B) starches of different amylose concentrations. - $\square-, 0 \mathrm{~g}$ amylose/kg total starch; -- $\mathbf{\Delta - - ,} 270 \mathrm{~g}$ amylose/kg total starch; -O-, $600 \mathrm{~g}$ amylose $/ \mathrm{kg}$ total starch; -----, $850 \mathrm{~g}$ amylose $/ \mathrm{kg}$ total starch. For details of subjects and procedures, see p. 824. Values are means with their standard errors shown by vertical bars ( $n 7)$.

the uncooked starches, as a low amylose content causes maximal attenuation of insulinaemic response under this condition.

The amount of carbohydrate fed per meal in the present study is comparable with that used in oral glucose tolerance tests by other investigators (e.g. Byrnes et al. 1995). The small size of this meal (mean value $0.4 \mathrm{~g}$ ) facilitated relatively uniform and complete consumption of the meal by all animals. In addition, a small meal size reflects the nibbling nature of a rat's natural eating pattern and is therefore physiologically appropriate for use in a rodent model.

The higher amylose $(600$ and $850 \mathrm{~g}$ amylose $/ \mathrm{kg}$ total starch) meals produced a significant reduction in insulinaemic response compared with the $0 \mathrm{~g}$ amylose $/ \mathrm{kg}$ total starch meal in both the uncooked and cooked form. This is presumably due to the higher gelatinisation temperature of high-amylose starches $\left(154-171^{\circ} \mathrm{C}\right)$ compared with waxy maize starch $\left(<70^{\circ} \mathrm{C}\right)$ (Doublier \& Chopin, 1989), 

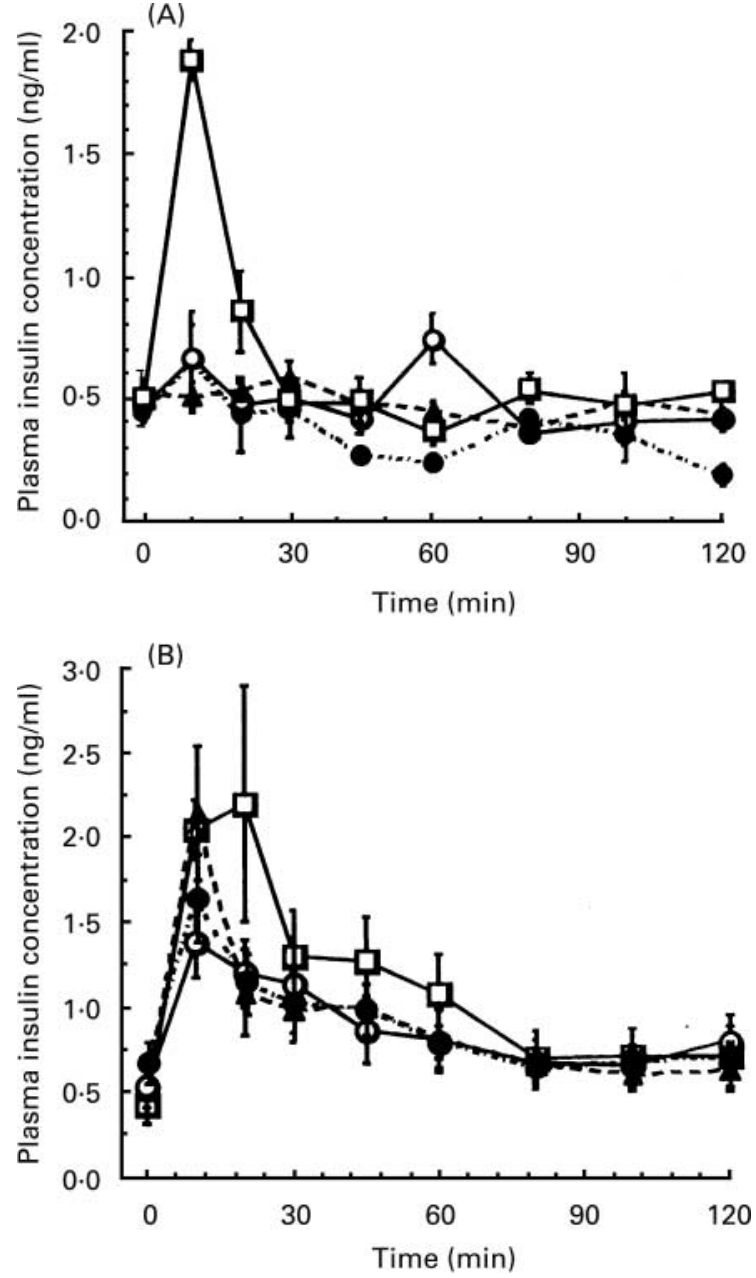

Fig. 2. Postprandial plasma insulin concentrations in response to cooked (A) or uncooked (B) starches of different amylose concentrations. - $\square-, 0 \mathrm{~g}$ amylose/kg total starch; -- $\Delta--, 270 \mathrm{~g}$ amylose/kg total starch; -O-, $600 \mathrm{~g}$ amylose/kg total starch; - - $-850 \mathrm{~g}$ amylose $/ \mathrm{kg}$ total starch. For details of subjects and procedures, see p. 824. Values are means with their standard errors shown by vertical bars $(n 7)$.

which enables the granules to maintain their structure and conformation even after cooking.

The postprandial glycaemic and insulinaemic excursions were substantially higher for cooked than uncooked starches (Fig. 3). However, basal insulin concentrations were similar for all rats. The process of cooking the high-amylose starches to $80^{\circ} \mathrm{C}$ in a low-solids aqueous suspension resulted in a decrease in the amount of dietary fibre contained in the starches. While this may explain some of the difference in the 600 and $850 \mathrm{~g}$ amylose $/ \mathrm{kg}$ total starch groups, it does not explain the differences between the 0 and $270 \mathrm{~g}$ amylose $/ \mathrm{kg}$ total starch groups, where the fibre content was very low and equivalent between the cooked and uncooked starches.

It has been shown that postprandial insulin levels can be decreased slightly when one-third of the carbohydrate in a test meal is an $850 \mathrm{~g}$ amylose $/ \mathrm{kg}$ total starch rather than an amylopectin-based starch (Noakes et al. 1996). However, definitive dose-response curves for the postprandial insulinaemic and glycaemic effects of meals of differing

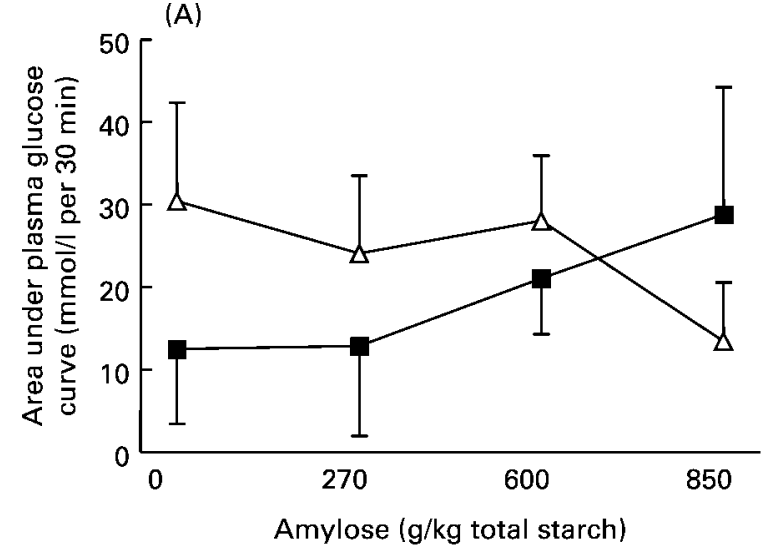

(B)

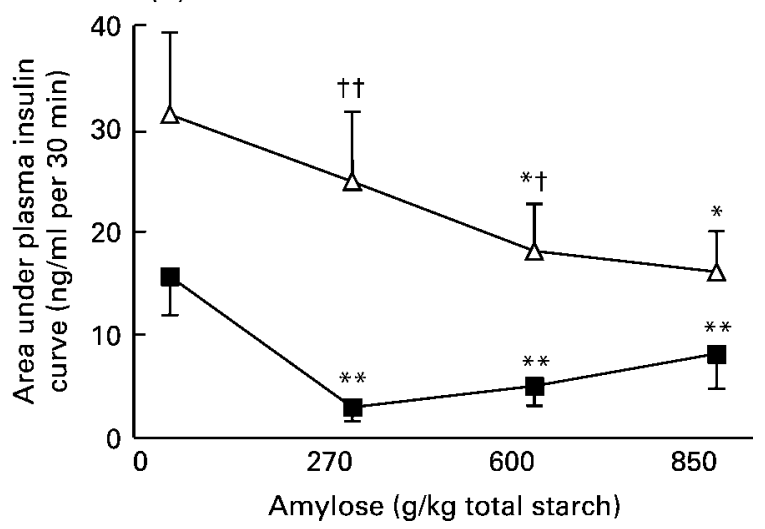

Fig. 3. Incremental area under the curve for glucose $(A)$ and insulin (B) in response to meals of different amylose concentration. Uncooked; $\triangle$, cooked. For details of subjects and procedures, see p. 824. Values are means with their standard errors shown by vertical bars $(n 7)$. Mean values were significantly different from those of the $0 \mathrm{~g} / \mathrm{kg}$ amylose group in the same category (i.e. cooked or uncooked): ${ }^{\star} P=0.0075,{ }^{\star \star} P=0.001$. Mean values were significantly different from those of the uncooked starch of the same amylose concentration $(\dagger P=0.0068, \dagger \dagger P=0.0009)$.

amylose concentrations had not previously been determined. Results presented here indicate that, in rats, diets high in waxy maize starches $(0 \mathrm{~g}$ amylose $/ \mathrm{kg}$ total starch group) led to relatively high insulinaemic excursions after meals. Regular maize starch ( $270 \mathrm{~g}$ amylose $/ \mathrm{kg}$ total starch) appears to have some resistance to digestion in the granular form, leading to a decrease in postprandial insulin response. However, this resistance is largely lost following cooking, when the postprandial insulinaemic response is similar to that for $0 \mathrm{~g}$ amylose $/ \mathrm{kg}$ total starch (Fig. 1(B)). Therefore, there may be no dietary advantage in consuming foods containing regular maize ( $270 \mathrm{~g}$ amylose $/ \mathrm{kg}$ total starch) rather than waxy maize $(0 \mathrm{~g}$ amylose/kg total starch). Conversely, higher amylose (600 and $850 \mathrm{~g}$ amylose $/ \mathrm{kg}$ total starch) meals produced a significant reduction in insulinaemic response compared with the $0 \mathrm{~g}$ amylose $/ \mathrm{kg}$ total starch meal in both the uncooked and cooked form, and may confer some metabolic benefit when consumed as part of a mixed meal.

The results presented herein show that in the uncooked form, only $270 \mathrm{~g}$ amylose $/ \mathrm{kg}$ total starch is required to achieve a maximal attenuating effect on postprandial 
insulin concentrations as compared with $0 \mathrm{~g}$ amylose $/ \mathrm{kg}$ total starch. Following cooking, however, at least $600 \mathrm{~g}$ amylose $/ \mathrm{kg}$ total starch is needed to achieve a similar effect. These results have important ramifications for the design of human feeding studies using high-amylose starches: these studies often utilise foods in the cooked state.

\section{Acknowledgements}

Vitamin and mineral mixes were a gift from Millmaster Feeds, Enfield, Australia. Starches were donated by Penford Australia Limited, Lane Cove, Australia.

\section{References}

Association of Official Analytical Chemists (1995) Total dietary fibre in foods: enzymatic-gravimetric method (method 985.29). In Official Methods of Analysis, 16th ed. Arlington, VA: AOAC.

Annison G \& Topping DL (1994) Nutritional role of resistant starch: chemical structure vs. physiological function. Ann Rev Nutr 14, 297-320.

Byrnes SE, Brand Miller JC \& Denyer GS (1995) Amylopectin starch promotes the development of insulin resistance in rats. J Nutr 125, 1430-1437.

Doublier JL \& Chopin L (1989) A rheological description of amylose gelation. Carbohydr Res 193, 215-226.
Granfeldt Y (1994) Glucose and insulin responses to barley products: influence of food structure and amylose-amylopectin ratio. Am J Clin Nutr 59, 699S-705S.

Higgins JA, Brand Miller JC \& Denyer GS (1996) Development of insulin resistance in the rat is dependent on the rate of glucose absorption from the diet. J Nutr 126, 596-602.

Morris KL \& Zemel MB (1999) Glycemic index, cardiovascular disease, and obesity. Nutr Rev 57, 273-276.

Noakes M, Clifton PM, Nestel PJ, Le Leu R \& McIntosh G (1996) Effect of high-amylose starch and oat bran on metabolic variables and bowel function in subjects with hypertriglyceridemia. Am J Clin Nutr 64, 944-951.

Pascoe WS, Jenkins AB, Kusunoki M \& Storlien LH (1992) Insulin action and determinants of glycaemia in a rat model of Type 2 (non-insulin-dependent) diabetes mellitus. Diabetologia 35, $208-215$.

Salmeron J, Ascherio A, Rimm EB, et al. (1997a) Dietary fiber, glycemic load, and risk of NIDDM in men. Diabetes Care 20, 545-550.

Salmeron J, Manson JE, Stampfer MJ, Colditz GA, Wing AL \& Willett WC (1997b) Dietary fiber, glycemic load, and risk of non-insulin-dependent diabetes mellitus in women. JAMA 277, 472-477.

Siljestrom M \& Asp N (1985) Resistant starch formation during baking - Effect of baking time and temperature and variations in recipe. Z Lebensm Unters Forsch 181, 4-8.

Storlien LH, Kraegen EW, Jenkins AB \& Chisholm DJ (1988) Effects of sucrose vs starch diets on in vivo insulin action, thermogenesis, and obesity in rats. Am J Clin Nutr 47, $420-427$. 